\title{
BMJ Open Occupational outcomes following mild traumatic brain injury in Canadian military personnel deployed in support of the mission in Afghanistan: a retrospective cohort study
}

\author{
Bryan G Garber, ${ }^{1}$ Corneliu Rusu, ${ }^{1}$ Mark A Zamorski, ${ }^{1,2}$ David Boulos ${ }^{1}$
}

To cite: Garber BG, Rusu C, Zamorski MA, et al. Occupational outcomes following mild traumatic brain injury in Canadian military personnel deployed in support of the mission in Afghanistan: a retrospective cohort study. BMJ Open 2016;6: 010780. doi:10.1136/bmjopen-2015010780

- Prepublication history for this paper is available online. To view these files please visit the journal online (http://dx.doi.org/10.1136/ bmjopen-2015-010780).

Received 5 January 2016 Revised 26 February 2016 Accepted 11 April 2016

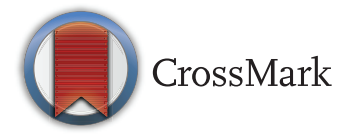

${ }^{1}$ Canadian Forces Health Services Group Headquarters, Ottawa, Ontario, Canada ${ }^{2}$ Faculty of Medicine, Department of Family Medicine, University of Ottawa, Ottawa, Ontario, Canada

Correspondence to Dr Bryan G Garber; bryan.garber@forces.gc.ca

\section{ABSTRACT}

Objective: Deployment-related mild traumatic brain injury (MTBI) occurs in a significant number of military personnel but its long-term impacts are unclear. This study explores the impact of deployment-related MTBI on continued fitness-for-duty, with the ultimate intent of identifying potential targets for intervention to attenuate its effects.

Participants: Consisted of 16193 Canadian Armed Forces (CAF) personnel who deployed in support of the mission in Afghanistan and completed an enhanced postdeployment screening (EPDS) questionnaire over the period January 2009-July 2012.

Primary outcome: The primary outcome was development of permanent medical unfitness defined as a 'career-limiting medical condition' (CL-MC). The secondary outcome was the diagnostic categories recorded for each individual at the time a CL-MC was established.

Design: This study used a retrospective cohort design. Linked administrative and health data provided the primary outcome and the diagnoses responsible for it. Survival analysis was used to estimate the risk of a CL-MC and Cox regression provided adjusted HRs (aHRs) for the association between a CL-MC and MTBI, accounting for key covariates and confounders. Diagnostic categories associated with CL-MCs were identified.

Results: Over a median follow-up period of 3.42 years, $6.57 \%$ of the study population developed a CL-MC. MTBI was independently associated with CL-MCs (aHR=1.65, 95\% Cl 1.35 to 2.03). Mental disorders and musculoskeletal conditions were the primary diagnoses associated with CL-MCs (identified as the primary diagnosis in $55.4 \%$ and $25.9 \%$, respectively), and a neurological condition was only documented in $5.8 \%$ of those with MTBI who developed a CL-MC

Conclusions: Deployment-related MTBI was associated with adverse occupational outcome but mental disorders and musculoskeletal conditions primarily drove subsequent medical unfitness. These findings support a diagnostic and treatment approach focusing on these comorbidities as the most promising

\section{Strengths and limitations of this study}

- Mild traumatic brain injury was assessed through self-reports, raising the possibility of recall bias and reporting errors.

- We were only able to control for mental health problems, postconcussive symptoms and musculoskeletal pain reported at the time of screening, which took place several years, on average, before the outcome. It is possible that problems reported at that time had resolved or, conversely, that subsequent problems in those areas had developed at the time medical fitness problems were identified.

- The large sample size allowed us to control for a broad range of covariates and potential confounders.

- The length of follow-up exceeds that in many other published studies on the topic.

strategy to minimise the burden of disability in MTBIexposed military personnel.

\section{INTRODUCTION}

Mild traumatic brain injury (MTBI) is reported by up to a quarter of military personnel who deployed to the conflicts in Southwest Asia. ${ }^{1}$ By definition, MTBI is associated with changes in mental status (eg, loss of consciousness, or being dazed or confused) at the moment of injury. Transient symptoms such as headache, irritability and problems concentrating typically occur acutely and resolve spontaneously in most individuals days to weeks after the injury. However, in some individuals these same symptoms remain beyond 3 months and are referred to as persistent postconcussive symptoms (PCS). ${ }^{2}$

Estimates of the prevalence of persistent PCS vary. Approximately, one-quarter of the 
Canadian Armed Forces (CAF) personnel with a deployment-related MTBI reported three or more PCS 6 months after their return from deployment, ${ }^{3}$ a fraction similar to or below those reported in US military personnel (up to $33 \%)^{4}$ but above those seen in civilian accident victims (up to $15 \%$ ) and in those with sport-related concussions. ${ }^{56}$

The pathophysiology of these persistent PCS remains unclear, but they have strong conceptual and empirical links with mental disorders and other psychosocial factors. ${ }^{5}$ In recent combat operational settings, blast is one of the most common mechanisms of MTBI. ${ }^{7}{ }^{8}$ Consequently, MTBI often co-occurs with psychological injury and other serious physical injuries, complicating the clinical picture. ${ }^{9}$ Regardless, persistent PCS are associated with impairments in well-being and functioning. ${ }^{10}{ }^{11}$ Conceptually, their impacts could be especially strong under the demands of military service. However, while studies on the incidence and prevalence of deployment-related MTBI in military personnel abound, ${ }^{3}{ }^{4} 12$ studies on functional outcomes are sparse. ${ }^{8}$

This paucity of research on long-term functional impacts of deployment-related MTBI stands in stark contrast to the profusion of dire predictions of the impact of this 'signature injury' of the conflicts in Southwest Asia. ${ }^{13}$ To address these concerns, the US Departments of Defence and of Veterans Affairs have ramped up efforts to diagnose MTBI and to provide cognitive rehabilitation and other MTBI-specific services in those with persistent symptoms. ${ }^{14}$ The approach of the CAF has been different, focusing instead diagnosis and treatment of comorbid mental disorders and a symptom-specific approach for those with persistent, unexplained symptoms. ${ }^{15}$

This paper explores one important long-term impact of deployment-related MTBI, specifically its effect on continued fitness for military service. It uses self-report data on MTBI, mental health symptoms, musculoskeletal pain and PCS collected during postdeployment mental health screening, linked with subsequent administrative data on occupational impairments. Its two main objectives were to:

1. Determine whether those who self-reported MTBI at the time of postdeployment screening were more likely to be medically unfit compared with those without MTBI after controlling for comorbid mental and physical conditions as well as other potential confounders;

2. Determine the primary diagnoses to which medical unfitness was attributable in those with deploymentrelated MTBI.

\section{METHODS}

\section{Context: Canada's mission in Afghanistan}

The CAF has deployed more than 40000 personnel in support of their combat and peace support mission in Afghanistan. More than 150 deaths occurred, most related to injuries from improvised explosive devices.

\section{Study design}

This was a retrospective longitudinal cohort study that integrated administrative and medical data in a cohort of CAF personnel.

\section{Respondents}

Respondents were 16193 CAF personnel who deployed in support of the mission in Afghanistan and completed an enhanced postdeployment screening (EPDS) questionnaire over the period January 2009-July 2012. CAF policy requires an EPDS 90-180 days after return for personnel deployed for 60 days or more. Participants had deployed largely for 6-8 months to Kandahar Province (Afghanistan) or in the Persian Gulf region, where they fulfilled a broad range of combat, peacekeeping, operational support, administrative and other roles. Participants were screened a median of 136 days after return from deployment (IQR: 100-178 days). Compliance with EPDS is at least $76 \%$. $^{16}$

\section{Data collection}

Data on MTBI, mental-health problems, PCS, musculoskeletal pain and combat exposure were extracted from the EPDS database. Data on sociodemographic and military characteristics, disability and the diagnoses driving disability were obtained from administrative databases (extract date: 17 October 2013). Data linkages were based on service number, a unique CAF-specific personal identifier.

\section{Covariates of interest and potential confounders Mild traumatic brain injury}

MTBI was assessed using the first two questions of the Brief Traumatic Brain Injury Screening Tool. ${ }^{17}$ The first item assesses injury during the deployment from the following mechanisms: fragment, bullet, vehicular, fall, blast or any other mechanism. The second item assesses symptoms of altered mental status immediately after the injury. The screen is considered positive in those with injury associated with being dazed, confused or seeing stars, having loss of consciousness or having posttraumatic amnesia. This criterion is $80 \%$ sensitive and 93\% specific for clinician-diagnosed deployment-related MTBI. ${ }^{18}$ To keep the focus of the study on MTBI, participants reporting loss of consciousness of $>20 \mathrm{~min} \quad(n=40)$ were excluded, leaving 16153 in the final data set.

\section{Postconcussive symptoms (PCS)}

Seven PCS were assessed at the time of postdeployment screening: (headache, dizziness, memory problems, fatigue, difficulty concentrating, insomnia and irritability), using items and thresholds described in detail elsewhere. A PCS case was defined as having three or more of these symptoms. This definition is modelled after the WHO International Classification of Diseases 10th edition (ICD-10) definition for postconcussion syndrome and is commonly used in other studies for 
exploring the relationship between MTBI, postconcussive symptoms and mental health problems. ${ }^{4} 19$

\section{Common mental health problems}

Common mental health problems (MHP's) were assessed as described elsewhere using instruments that did not include physical symptoms that overlap with those defined in the ICD-10 definition of PCS, such as feeling tired, trouble concentrating, sleep problems and irritability. Specifically, depression was assessed with the 2-item Patient Health Questionnaire (PHQ)-2 ${ }^{20}$ with a cut-off point of 4 or greater. ${ }^{21}$ Post-traumatic stress disorder (PTSD) was assessed using the 2-item PTSD checklist (PCL)-2 with a cut-off of 6 points or greater. $^{22} 23$ Panic disorder was assessed using the PHQ, with a modified algorithm that did not require the presence of four or more symptoms during the most recent panic attack. ${ }^{24}$

\section{Back and joint pain}

These were assessed using two items from the PHQ physical symptom inventory (recall period=4 weeks; response categories='not at all', 'bothered a little', and 'bothered a lot'). The aggregate outcome of 'back or joint pain' included those who reported being 'bothered a lot' on one or both of these items.

\section{Combat exposure}

A modified, 30-item version of the scale developed by Walter Reed Army Institute for Research (US) was used to measure the extent of combat exposure. ${ }^{25}$ Each item was a yes/no question regarding having experienced specific potentially traumatic experiences while deployed, and the scale score was simply the sum of positive responses (range $0-30, \alpha=0.91$ ). For analysis purposes, the scale score was divided into tertiles, determined with respect to a larger reference population of CAF personnel undergoing postdeployment screening after a number of different military operations since 2009.

\section{Sociodemographic and military characteristics}

These potential confounders were assessed using items developed for the EPDS questionnaire: sex, age, language (English or French), marital status, rank, component (regular vs reserve force), element (Army, Navy or Air Force), years of military service, number of previous deployments, deployment length and timing of screening relative to return from deployment. Missing data were filled in where possible using administrative data sources.

\section{Occupational outcomes}

\section{Occupational fitness in the CAF}

Military service is physically and psychologically demanding. The medical fitness requirements for service are commensurately stringent and vary with the tasks specific to different military occupations. However, like all militaries, there is a common set of core essential tasks that all individuals must be capable of performing in order to serve in uniform in the CAF. In addition, all military personnel need to be able to deploy to any location with little or no medical support. ${ }^{26}$

On enrolment, every member undergoes a thorough medical examination and is assigned a medical category. This medical category is a numeric profile that summarises to chain of command key information about a member's employability within their given military trade. The factors included in a medical category are: visual acuity, colour vision, hearing, geographical factor, occupational factor and air factor. ${ }^{27}$

For most disorders, the 'geographical' and 'occupational' factor codes drive retention decisions. The geographical factor captures an individual's need for medical care that might be unavailable at potential work locations (eg, during deployment). The occupational factor captures an individual's capacity to perform required job functions under the physical and mental stress associated with operational conditions. The codes for the geographical and occupational factors can range from 1 to 6; higher grades represent more severe limitations.

When a CAF member is ill or becomes injured, they are required to be assessed by a CAF medical officer (a physician) all of whom are experienced in the practice of occupational medicine. A thorough medical assessment, diagnosis and treatment plan is developed. The medical officer also has a responsibility to inform the chain of command as to any health-related employment limitations that impact the member's ability to perform expected tasks and duties safely. This information is expressed in the form of written medical employment limitations (MELs).

These temporary MELs will result in a temporary change to one or more medical category factors while waiting for a medical condition to ameliorate. If the medical condition has plateaued and/or is not expected to significantly improve in the foreseeable future, a permanent medical category change is assigned.

Throughout the process described, individual base/ unit military medical physicians do all determinations of MELs and medical category changes. However, all permanent medical category changes are required to undergo a centralised review. This review is conducted by the Medical Standards Section in the Canadian Forces Health Services Group Headquarters in Ottawa for a final determination. The purpose of this centralised review is to ensure consistency in the application of MELs and medical categories.

CAF members with permanent medical category changes as a result of health conditions undergo a separate review by a career board who then determine if the individual can remain in their current occupation. If they cannot perform the essential tasks required of all military members, and/or are deemed to be unable to deploy to any location with little or no medical support, they will ultimately be medically released. 


\section{Outcome definitions}

The primary outcome was defined as the development of a 'career-limiting medical condition' (CL-MC), meaning a permanent medical category that reliably results in a medical release from service. ${ }^{28}$ This outcome was used instead of a medical discharge from service because there is an unpredictable delay of up to several years between the recognition of CL-MC and ultimate discharge. Consultation with physicians in the Medical Standards Section identified certain patterns of category changes, primarily based on the geographic and occupational factors, encoded in administrative data that reliably result in medical release. ${ }^{28}$

The secondary outcome was the diagnostic category recorded in the Medical Standard's Database for each individual at the time a CL-MC was established. This includes one primary and up to two secondary diagnostic categories (eg, mental disorders, cardiovascular disorder) that are driving the CL-MC. There is no specific diagnostic category for TBI; those with TBI are captured in the category of neurological conditions.

\section{Statistical analysis}

The data were analysed using SAS for Windows, V.9.3. The chained equations multiple imputation method was implemented to account for missing data. ${ }^{29}$ Overall, $<1 \%$ of the analysed data had missing values.

Time to event analysis was used to account for differing periods of follow-up and censoring. Kaplan-Meier curves were used to generate event probabilities. Zero time was defined as the return date from the first Afghanistan-related deployment. Event time was the date of the medical exam associated with the first persistent CL-MC designation. Individuals were censored at the earlier of military service discharge date or database extraction date.

Cox regression modelled the association of injury status with CL-MC risk. The proportional hazards assumption was examined using Schoenfeld residual plots and with an assessment of the significance of changes in the injury status HR as the logarithm of follow-up time increased. ${ }^{30}$ We used four models to estimate the unadjusted and adjusted HRs for injury status. Model 1 estimated the unadjusted risk; Model 2 estimated the adjusted risk controlling for sociodemographic and military characteristics. In addition to these factors, Model 3 adjusted for mental disorders and persistent PCS, while Model 4 additionally adjusted for severe back or joint pain.

The rank, years of military service, number of previous deployments and duration of last deployment variables were measured with respect to the first deployment return date. Injury status, presence of a mental disorder, PCS and severe back or joint pain variables were measured with respect to the EPDS date.

\section{RESULTS}

\section{Study cohort characteristics}

The cohort consisted largely of male, non-commissioned Army personnel under the age of 40 years, who were in the regular force (table 1). MTBI was reported in $5.22 \%$ and other non-MTBI injuries were documented in $16.76 \%$. Symptoms of major depression, PTSD and panic disorder were reported at postdeployment screening in $3.67 \%, 5.70 \%$ and $1.94 \%$, respectively, while any of the three mental health problems was reported in $8.80 \%$. Bothersome back or joint pain was reported by $17.83 \%$. Finally, three or more PCS were present at the time of EPDS in $8.69 \%$.

\section{Career-limiting medical conditions}

A total of $6.57 \%$ had a CL-MC recorded over a median follow-up time of 3.42 years (IQR: 2.71-4.29 years). At 5 years of follow-up, those who self-reported a deployment-related MTBI had a probability of CL-MC of $26.1 \%$ (95\% CI $21.6 \%$ to $31.5 \%$ ) compared with $17.2 \%$ (95\% CI $14.9 \%$ to $19.8 \%$ ) in those with other injuries and $8.0 \%$ (95\% CI $7.2 \%$ to $8.9 \%$ ) for those with no injuries (figure 1 and table 2).

\section{Diagnostic categories driving CL-MC}

While those reporting MTBI had an elevated risk of adverse occupational outcome, clinicians seldom attributed a CL-MC to a neurological condition: Of those reporting deployment-related MTBI who developed a CL-MC, 5.8\% had a neurological condition identified as a primary or secondary contributing diagnosis (table 3) and only $4.3 \%$ had a neurological condition identified as the primary contributing diagnosis (data not shown). Instead, mental disorders $(64.8 \%)$ and musculoskeletal conditions $(51.1 \%)$ were the predominant diagnoses recorded for CL-MCs (identified also as the primary diagnosis) in $55.4 \%$ and $25.9 \%$, respectively (data not shown).

Given the potential difficulty in attributing disability to MTBI, mental disorders and musculoskeletal conditions in military personnel exposed to psychological and physical trauma, four regression models were created in order to examine changes in the injury status HR as additional covariates, including proxies for psychological and physical injury (table 4).

Model 1 shows the unadjusted risk of a CL-MC for those with a history of MTBI (HR, 3.17 (95\% CI 2.64 to 3.81)) was significantly higher than for non-MTBI injury (HR, 2.05 (95\% CI 1.78 to 2.35$)$ ), relative to the uninjured. The risk of a CL-MC for those with a history of MTBI had decreased in the final model (Model 4), but remained modestly elevated adjusted HR (aHR, 1.65 (95\% CI 1.35 to 2.03$)$ ). The presence of any mental disorder (aHR, 2.55 (95\% CI 2.15 to 3.02)), three or more PCS (aHR, 1.87 (95\% CI 1.57 to 2.23)) and musculoskeletal pain (aHR, 1.63 (95\% CI 1.42 to 1.87 )) also had an increased risk of CL-MC. 
Table 1 Demographic, military characteristic and type of diagnosis of the study cohort $(n=16153)$

\begin{tabular}{|c|c|c|}
\hline & Count & Per cent \\
\hline \multicolumn{3}{|l|}{ Sex } \\
\hline Male & 14641 & 90.67 \\
\hline Female & 1507 & 9.33 \\
\hline Total & 16148 & \\
\hline \multicolumn{3}{|l|}{ Age } \\
\hline 24 years or less & 3134 & 19.42 \\
\hline $25-35$ years & 7075 & 43.84 \\
\hline $35-44$ years & 4049 & 25.09 \\
\hline 45 years or more & 1882 & 11.66 \\
\hline Total & 16140 & \\
\hline \multicolumn{3}{|l|}{ Rank } \\
\hline Officer & 2331 & 14.45 \\
\hline Senior NCM & 2863 & 17.75 \\
\hline Junior NCM & 10940 & 67.81 \\
\hline Total & 16134 & \\
\hline \multicolumn{3}{|l|}{ Component } \\
\hline Reserve Force & 2339 & 14.48 \\
\hline Regular Force & 13812 & 85.52 \\
\hline Total & 16151 & \\
\hline \multicolumn{3}{|l|}{ Element } \\
\hline Land & 12824 & 79.54 \\
\hline Sea & 959 & 5.95 \\
\hline Air & 2340 & 14.51 \\
\hline Total & 16123 & \\
\hline \multicolumn{3}{|c|}{ Years of military service } \\
\hline 5 years or less & 5236 & 32.42 \\
\hline $6-15$ years & 6240 & 38.64 \\
\hline 16 years or more & 4675 & 28.95 \\
\hline Total & 16151 & \\
\hline \multicolumn{3}{|l|}{ Previous deployments } \\
\hline None & 7516 & 46.96 \\
\hline 1 or 2 & 5025 & 31.40 \\
\hline 3 or more & 3464 & 21.64 \\
\hline Total & 16005 & \\
\hline \multicolumn{3}{|l|}{ Deployment length } \\
\hline$<180$ days & 2284 & 14.16 \\
\hline 180 or more days & 13853 & 85.84 \\
\hline Total & 16137 & \\
\hline \multicolumn{3}{|l|}{ Combat exposure } \\
\hline 1st tertile & 4535 & 28.41 \\
\hline 2nd tertile & 6397 & 40.08 \\
\hline 3rd tertile & 5029 & 31.51 \\
\hline Total & 15961 & \\
\hline \multicolumn{3}{|l|}{ MTBI } \\
\hline No injury & 12602 & 78.02 \\
\hline Other injury & 2708 & 16.76 \\
\hline MTBI & 843 & 5.22 \\
\hline Total & 16153 & \\
\hline \multicolumn{3}{|l|}{$\mathrm{MHP}^{*}$} \\
\hline No MHP & 14058 & 91.20 \\
\hline MHP & 1356 & 8.80 \\
\hline Total & 15414 & \\
\hline \multicolumn{3}{|l|}{3 or more PCS } \\
\hline No & 14712 & 91.31 \\
\hline Yes & 1401 & 8.69 \\
\hline Total & 16113 & \\
\hline \multicolumn{3}{|c|}{$\begin{array}{l}\text { *Any mental disorder defined as any of the following: major } \\
\text { depression (Patient Health Questionnaire (PHQ)-2), post-traumatic } \\
\text { stress disorder (PTSD) (2-item PTSD checklist (PCL)) or panic } \\
\text { disorder. } \\
\text { MHP, mental health problem; MTBI, mild traumatic brain injury; } \\
\text { NCM, non-commissioned member; PCS, postconcussive } \\
\text { symptoms. }\end{array}$} \\
\hline
\end{tabular}

Given the residual effect of three or more PCS on outcome, a post hoc analysis was conducted to determine whether three or more PCS was mediating the association between MTBI and CL-MCs using SAS MEDIATE macro. ${ }^{31}$ This revealed that PCS only mediated $3.65 \%$ (95\% CI $0.22 \%$ to $7.09 \%)$ ) of the relationship between MTBI and CL-MCs.

Combat exposure, age 35 years or more, being of senior or junior non-commissioned rank, and having more than 15 years of military service also showed increased risk of CL-MCs (table 4). Sex, element (Army, Navy or Air Force), number of previous deployments and duration of last deployment were not associated with CL-MC.

\section{DISCUSSION}

\section{Summary of key findings}

The ultimate objective of this paper was to determine the effect of deployment-related MTBI on subsequent medical unfitness defined by the development of CL-MC. MTBI was indeed associated with a substantial absolute and relative risk of this outcome $(26.1 \%$ within 5 years after return from deployment), well above the corresponding risk in the uninjured $(8.0 \%)$. Those with non-MTBI injuries had an intermediate risk $(17.2 \%)$.

However, only $5.8 \%$ of those with MTBI who developed a CL-MC had a neurological condition identified as a diagnosis contributing to their CL-MC designation. Instead, mental disorders and musculoskeletal conditions predominated.

We further explored the association of MTBI with CL-MCs using Cox regression. MTBI remained associated with the development of a CL-MC, even after adjustment for potential confounders, including mental health problems, PCS and musculoskeletal pain reported at the time of postdeployment screening (aHR for MTBI vs no injury=1.65 (95\% CI 1.35 to 2.03)). Finally, the effect of deployment-related MTBI on medical fitness was at most minimally mediated by PCS.

\section{Comparison with other findings}

To the best of our knowledge, this is the first study to systematically examine the effect of deployment-related MTBI on disability, specifically the development of CL-MCs that are incompatible with continued military service.

The only similar military study examined the extent to which musculoskeletal disorders impacted subsequent determinations of lack of medical fitness in a large cohort of US Army personnel. ${ }^{32}$ Coherent with our findings, those authors identified a mental disorder (specifically post-traumatic stress disorder) and a musculoskeletal condition (low back pain) as the two leading causes of lack of medical fitness. However, MTBI was identified as the third most common cause in that study, but the actual prevalence of MTBI is not reported, 
Figure 1 Kaplan-Meier

estimates of the probability of

career-limiting medical conditions

by type of injury.CL-MC,

career-limiting medical conditions.

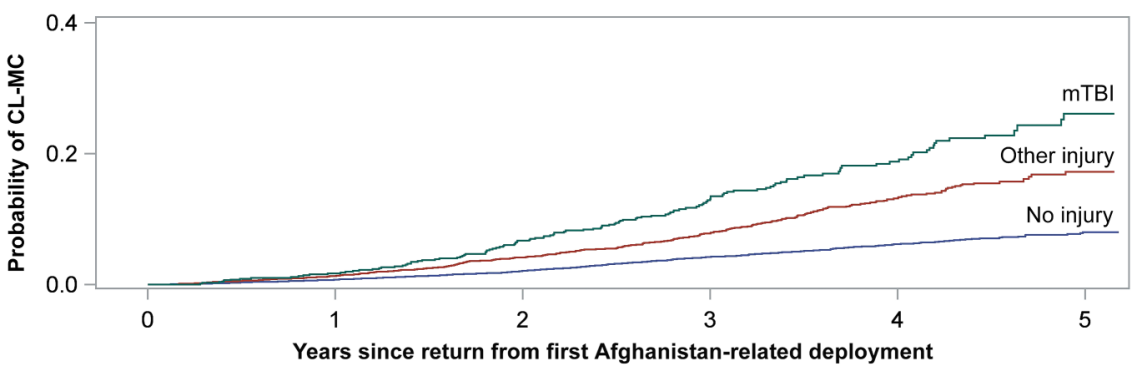

precluding any comparison with our study. Military studies of MTBI more than 6 months after deployment show a variety of adverse health effects, but none have explored occupational outcomes. ${ }^{8334}$

The comparative civilian literature on occupational impacts of MTBI is also limited. The Worker's Compensation Board of the Province of British Columbia in Canada found that $15 \%$ of MTBI claimants were on short-term disability for $>10$ weeks. ${ }^{34}$ A recent systematic review also reported that most workers with MTBI returned to work within 3-6 months after injury, and that MTBI did not appear to be a significant risk factor for long-term work disability. ${ }^{35}$ Our own finding of a high absolute risk of persistent occupational impairments after deployment-related TBI may relate to differences in patterns of comorbidity (notably, the high risk of psychological trauma and non-TBI injuries in those with deployment-related MTBI) in our population or to the stringent occupational fitness requirements for military personnel relative to civilians.

\section{Limitations and strengths}

We acknowledge the difficulty in attributing disability to MTBI as opposed to commonly comorbid conditions with overlapping symptoms such as mental disorders. Although we captured the clinician-indicated primary medical condition that contributed to the adverse occupational outcome and had covariates that measured psychological and physical injury as well as persisting PCS, we were not able to measure the changing nature of these variables with follow-up time.

All primary covariates of interest were assessed by selfreport at the time of non-anonymous, postdeployment screening. This raises several limitations: First, the lack of anonymity could potentially lead to under-reporting of mental health problems. Second, MTBI was assessed through self-reports using the brief traumatic brain injury screen used by the US. Recently, the sensitivity and specificity of this tool has been criticised. ${ }^{18}$ In addition, the fact that it relies on self-report (as do most) assessments of MTBI raises the possibility of recall bias and reporting errors. Current military case definitions for MTBI include those who were only dazed/confused or saw stars, which can lead to misclassification when head trauma coincides with psychological trauma in a combat setting. ${ }^{36}$ This will continue to be a challenge until such time as reliable objective diagnostic tests for MTBI are developed. Finally, we were only able to control for mental health problems, PCS and musculoskeletal pain reported at the time of screening, which took place several years, on average, before the outcome. It is possible that problems reported at that time had resolved or, conversely, that subsequent problems in those areas had developed at the time medical fitness problems were identified.

Our definition of PCS is also an important limitation: universally accepted research criteria for establishing postconcussive syndrome do not currently exist. The definition employed in this study was based on ICD-10 and has been used in other military studies, ${ }^{4}{ }^{19}$ but civilian research has shown that it is less specific than others. ${ }^{37}$ We strove to mitigate that potential effect by excluding anxiety and depression (present in the ICD-10 criteria) from our operational definition of PCS. Furthermore, depression and PTSD were evaluated using the PHQ-2 and PCL-2 scales that excluded symptoms considered for assessment of PCS.

The structure of the questionnaire precluded any determination of the nature of other injuries at the time of EPDS. These were likely musculoskeletal in nature

Table 2 Probability of career-limiting medical conditions $(95 \% \mathrm{Cl})$ by injury status at year of follow-up

\begin{tabular}{llrl}
\hline & \multicolumn{2}{l}{ Stratum } & \\
\cline { 2 - 4 } Years of follow-up & MTBI & Other injury & No injury \\
\hline 1 & $1.72(1.00$ to 2.95$)$ & $1.31(0.93$ to 1.84$)$ & $0.74(0.60$ to 0.91$)$ \\
2 & $6.72(5.14$ to 8.78$)$ & $4.17(3.45$ to 5.03$)$ & $2.08(1.84$ to 2.36$)$ \\
3 & $13.13(10.78$ to 15.93$)$ & $7.93(6.86$ to 9.14$)$ & $4.23(3.85$ to 4.65$)$ \\
4 & $19.10(16.00$ to 22.72$)$ & $13.27(11.70$ to 15.03$)$ & $6.21(5.68$ to 6.78$)$ \\
5 & $26.13(21.57$ to 31.45$)$ & $17.24(14.96$ to 19.83$)$ & $8.02(7.18$ to 8.96$)$ \\
\hline MTBI, mild traumatic brain injury. & & &
\end{tabular}




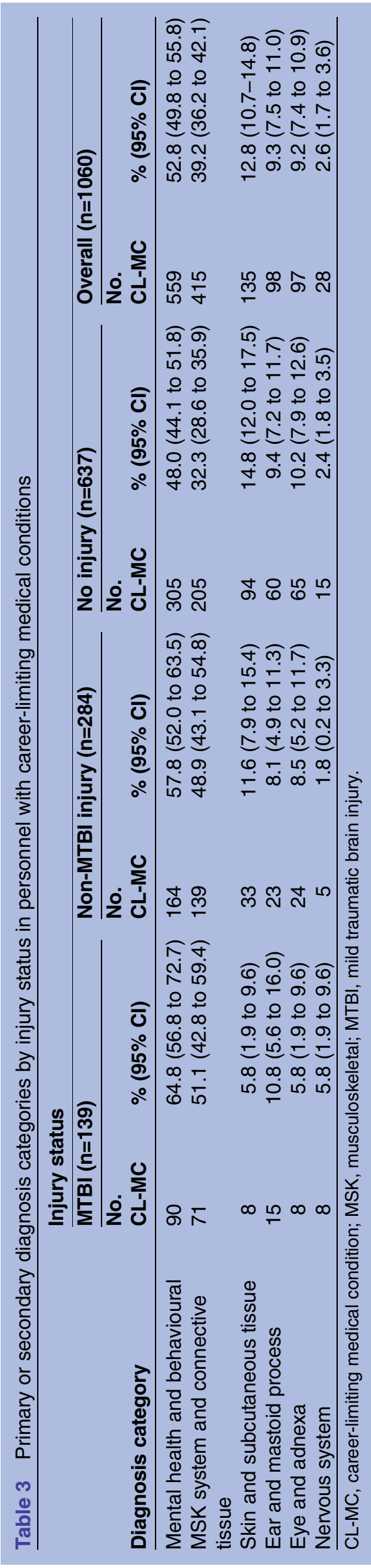

given findings from injury surveillance on military operations. $^{32}$

Although debate continues about the long-term effects of repeated MTBI, we did not have the ability to control for its potential effect in this study. ${ }^{38} 39$ It is therefore possible that much of the effect of MTBI on occupational impairment was due to multiple MTBI. Had this been the case, we would however have expected that the comprehensive assessment performed on all military personnel who are at risk of release on medical grounds should have uncovered this and be reflected in the estimates of neurological disorders as a driver of disability.

Finally, the results of this study are rooted in the CAF's unique occupational fitness standards and hence not directly generalisable to other military organisations or employers in other sectors.

This study's primary strength is that it explores an important but under-researched issue: the occupational impact of deployment-related MTBI in a military population. The large sample size allowed us to control for a broad range of covariates and potential confounders. The length of follow-up exceeds that in many other published studies on the topic. Finally, time-to-event analysis allowed for efficient use of the data.

\section{Implications}

Military personnel who report deployment-related MTBI are at significantly increased risk for adverse occupational outcomes. However, medical unfitness was largely driven by mental and musculoskeletal disorders and to a far lesser extent by neurological diagnoses. The pathogenesis of poor health in some individuals following MTBI remains poorly understood and is undoubtedly multifactorial in nature. ${ }^{40}$ Consequently, there is no consensus about how to mitigate adverse health outcomes in those with MTBI.

Given this challenge, military and veteran organisations in the US have increased their detection of MTBI through screening and outreach and have implemented MTBI-specific treatments such as cognitive rehabilitation. ${ }^{14}{ }^{41}$ Civilian guidelines have instead argued for a symptom-based approach in light of the multifactorial nature of persistent PCS. ${ }^{42}$ This approach emphasises detection and treatment of mental disorders when present. The CAF formally endorsed this approach in $2008 .^{15}$

The findings of the present study suggest that military attrition following deployment-related MTBI may best be mitigated by focusing on assessment and maximal treatment of mental disorders and musculoskeletal problems. Our observation that neurological diagnosis were an infrequent cause of medical unfitness in those with MTBI, and that PCS only weakly mediated the association of MTBI with adverse occupational outcome casts some doubt as to the potential benefit of the routine use of cognitive rehabilitation therapy given the lack of rigorously controlled studies in this context. ${ }^{43}$ 
Table 4 Cox proportional hazards models showing the risk of career-limiting medical conditions with demographic and military characteristics, injury status, mental health problems and persistent postconcussive symptoms

\begin{tabular}{|c|c|c|c|c|}
\hline Variable & $\begin{array}{l}\text { Model } 1^{*} \\
\text { aHR }(95 \% \mathrm{Cl})\end{array}$ & $\begin{array}{l}\text { Model } 2 \dagger \\
\text { aHR }(95 \% \mathrm{Cl})\end{array}$ & $\begin{array}{l}\text { Model 3¥ } \\
\text { aHR }(95 \% \mathrm{Cl})\end{array}$ & $\begin{array}{l}\text { Model } 4 \S \\
\text { aHR }(95 \% \mathrm{Cl})\end{array}$ \\
\hline \multicolumn{5}{|l|}{ Age } \\
\hline$\leq 24$ & - & 1.00 & 1.00 & 1.00 \\
\hline $25-34$ & & 1.33 (1.07 to 1.66$)$ & 1.25 (1.00 to 1.55$)$ & 1.24 (0.996 to 1.55$)$ \\
\hline $35-44$ & & 1.81 (1.37 to 2.39$)$ & $1.63(1.23$ to 2.15$)$ & 1.57 (1.19 to 2.07$)$ \\
\hline$\geq 45$ & & 2.88 (2.10 to 3.97$)$ & 2.62 (1.90 to 3.62$)$ & 2.48 (1.80 to 3.43$)$ \\
\hline \multicolumn{5}{|l|}{ Sex } \\
\hline Male & - & 1.00 & 1.00 & 1.00 \\
\hline Female & & $1.43(1.17$ to 1.76$)$ & $1.14(0.93$ to 1.39$)$ & $1.13(0.92$ to 1.39$)$ \\
\hline \multicolumn{5}{|l|}{ Rank } \\
\hline Officer & - & 1.00 & 1.00 & 1.00 \\
\hline Senior NCM & & 1.79 (1.38 to 2.32$)$ & 1.60 (1.23 to 2.07$)$ & 1.54 (1.19 to 2.00$)$ \\
\hline Junior NCM & & 2.55 (2.01 to 3.25$)$ & 2.18 (1.72 to 2.78$)$ & 2.09 (1.65 to 2.66$)$ \\
\hline \multicolumn{5}{|l|}{ Component } \\
\hline Reserve Force & - & 1.00 & 1.00 & 1.00 \\
\hline Regular Force & & $2.43(1.90$ to 3.11$)$ & 2.21 (1.73 to 2.84$)$ & 2.19 (1.71 to 2.81$)$ \\
\hline Element & - & & & \\
\hline Land & & 1.00 & 1.00 & 1.00 \\
\hline Sea & & $1.04(0.80$ to 1.35$)$ & $1.00(0.77$ to 1.30$)$ & $1.01(0.78$ to 1.31$)$ \\
\hline Air & & $1.00(0.83$ to 1.21$)$ & $1.07(0.88$ to 1.29$)$ & $1.05(0.87$ to 1.27$)$ \\
\hline Years of service & - & & & \\
\hline$\leq 5$ & & 1.00 & 1.00 & 1.00 \\
\hline $6-14$ & & $1.24(1.03$ to 1.49$)$ & $1.13(0.93$ to 1.35$)$ & $1.09(0.90$ to 1.31$)$ \\
\hline$\geq 15$ & & 1.86 (1.40 to 2.47$)$ & 1.64 (1.24 to 2.17$)$ & 1.58 (1.19 to 2.09$)$ \\
\hline Number of previous deployments & - & & & \\
\hline 0 & & 1.00 & 1.00 & 1.00 \\
\hline 1 or 2 & & 0.90 (0.78 to 1.05$)$ & $0.96(0.83$ to 1.11$)$ & $0.96(0.83$ to 1.11$)$ \\
\hline$\geq 3$ & & 0.84 (0.68 to 1.03$)$ & 0.90 (0.73 to 1.12$)$ & 0.91 (0.74 to 1.12$)$ \\
\hline Duration of last deployment (days) & - & & & \\
\hline$\leq 180$ & & 1.00 & 1.00 & 1.00 \\
\hline$>181$ & & 0.94 (0.79 to 1.12$)$ & $0.96(0.81$ to 1.14$)$ & $0.97(0.82$ to 1.16$)$ \\
\hline Combat exposuref & - & & & \\
\hline 1st tertile & & 1.00 & 1.00 & 1.00 \\
\hline 2nd tertile & & $1.44(1.20$ to 1.72$)$ & 1.25 (1.05 to 1.50$)$ & $1.23(1.03$ to 1.47$)$ \\
\hline 3rd tertile & & 2.06 (1.69 to 2.51$)$ & $1.52(1.24$ to 1.85$)$ & 1.49 (1.22 to 1.82$)$ \\
\hline \multicolumn{5}{|l|}{ Injury status } \\
\hline Uninjured & 1.00 & 1.00 & 1.00 & 1.00 \\
\hline Non-MTBI injury & 2.05 (1.78 to 2.35$)$ & 1.78 (1.54 to 2.05$)$ & $1.56(1.35$ to 1.81$)$ & $1.42(1.22$ to 1.65$)$ \\
\hline MTBI injury & 3.17 (2.64 to 3.81$)$ & 2.67 (2.20 to 3.25$)$ & 1.83 (1.49 to 2.24$)$ & 1.65 (1.35 to 2.03$)$ \\
\hline Any mental disorder** & - & - & & \\
\hline No & & & 1.00 & 1.00 \\
\hline Yes & & & 2.70 (2.28 to 3.21$)$ & 2.55 (2.15 to 3.02$)$ \\
\hline 3 or more PCS & - & - & & \\
\hline No & & & 1.00 & 1.00 \\
\hline Yes & & & 2.05 (1.72 to 2.44$)$ & 1.87 (1.57 to 2.23$)$ \\
\hline Severe back or joint pain & - & - & - & \\
\hline No & & & & 1.00 \\
\hline Yes & & & & $1.63(1.42$ to 1.87$)$ \\
\hline
\end{tabular}

*Model 1: unadjusted.

†Model 2: Model 1 adjusted for sociodemographic and military characteristics.

¥Model 3: Model 2 adjusted for mental disorders and PCS.

§Model 4: Model 3 adjusted for severe back or joint pain (based on PHQ-15).

१The following item cut-off was used for the combat exposure tertile categories: $<3$ items (1st tertile), 3-10 items (2nd tertile), more than 10 items (3rd tertile).

**Any mental disorder defined as any of the following: major depression (PHQ-2), PTSD (2-item PCL) or panic disorder.

$\mathrm{MTBI}$, mild traumatic brain injury; NCM, non-commissioned member; PCS, postconcussive symptoms. 
Additional research on outcome after MTBI is needed. Collecting information on the specific musculoskeletal problems driving disability in this population would provide useful context and might identify specific disorders for prevention and control efforts. Similarly, information on the timing of mental disorder onset might ultimately lead to interventions to facilitate early disclosure of symptoms and subsequent initiation of treatment.

\section{CONCLUSION}

The past decade has seen growing concern about the long-term impacts of deployment-related MTBI in military personnel. This study provides a clearer picture as to the extent of that risk. Adverse occupational outcomes in those with deployment-related MTBI were primarily driven by musculoskeletal conditions and mental disorders and to a far lesser extent by a neurological diagnosis. These findings support a more holistic diagnostic and treatment approach focusing on these comorbidities as the most promising strategy to minimise the burden of disability in MTBI-exposed military personnel.

Methodological refinements in future observational studies of outcome after MTBI will address some of the limitations of the present study. However, the question as to the optimal approach for treatment and rehabilitation of those with deployment-related MTBI will only be addressed definitively through carefully designed intervention trials.

Acknowledgements The authors are grateful for the contribution of Mrs. Julie Lanouette who assisted in elements of the data extraction.

Contributors All authors contributed substantially to the study. The primary author (BG) was responsible for the design, implementation and analysis of the manuscript. The second author (CR) managed the data acquisition and collection and conducted the statistical analyses. The third author (MZ) contributed to the design and implementation of the study. The fourth author (DB) contributed to the development of the statistical analytic approach. All authors contributed to the interpretation of the study results as well as the writing of the manuscript. All authors have read and agree with the manuscript's final content.

Funding This study was funded by 'The Canadian Forces Surgeon General's Health Research Program' (Protocol\# 2012-08-089-003-001).

Disclaimer Opinions expressed or implied in this publication are those of the authors, and do not represent the views or policy of the Department of National Defence or the Canadian Armed Forces. Parts of this work have previously been presented at the Canadian Military and Veteran's Health Research Forum in Toronto Canada, 25 November 2014.

Competing interests All authors are employees of the Canadian Department of National Defence and funding for this research came via this federal government department.

Ethics approval The study protocol was approved by Veritas Research Ethics Board (Montreal, Canada) and the Directorate of Access to Information and Privacy of the Department of National Defence.

Provenance and peer review Not commissioned; externally peer reviewed.

Data sharing statement No additional data are available.

Open Access This is an Open Access article distributed in accordance with the Creative Commons Attribution Non Commercial (CC BY-NC 4.0) license, which permits others to distribute, remix, adapt, build upon this work non- commercially, and license their derivative works on different terms, provided the original work is properly cited and the use is non-commercial. See: http:// creativecommons.org/licenses/by-nc/4.0/

\section{REFERENCES}

1. Center for Military Health Policy Research. Invisible wounds of war: psychological and cognitive injuries, their consequences, and services to assist recovery. In: Tanielian T, Jaycox LH, eds. Santa Monica, CA: RAND Corportation, 2008:1-453. http://www.rand.org/ pubs/monographs/MG720.html

2. Carroll LJ, Cassidy JD, Peloso PM, et al. Prognosis for mild traumatic brain injury: results of the WHO Collaborating Centre Task Force on Mild Traumatic Brain Injury. J Rehabil Med 2004;36(43 Suppl):84-105.

3. Garber BG, Rusu C, Zamorski MA. Deployment-related mild traumatic brain injury, mental health problems, and post-concussive symptoms in Canadian Armed Forces personnel. BMC Psychiatry 2014;14:325.

4. Terrio H, Brenner LA, Ivins BJ, et al. Traumatic brain injury screening: preliminary findings in a US Army Brigade Combat Team. J Head Trauma Rehabil 2009;24:14-23.

5. Iverson GL. Outcome from mild traumatic brain injury. Curr Opin Psychiatry 2005;18:301-17.

6. McCrea M, Guskiewicz KM, Marshall SW, et al. Acute effects and recovery time following concussion in collegiate football players: the NCAA Concussion Study. JAMA 2003;290:2556-63.

7. Hoge CW, McGurk D, Thomas JL, et al. Mild traumatic brain injury in U.S. Soldiers returning from Iraq. $N$ Engl J Med 2008;358:453-63.

8. Polusny MA, Kehle SM, Nelson NW, et al. Longitudinal effects of mild traumatic brain injury and posttraumatic stress disorder comorbidity on postdeployment outcomes in national guard soldiers deployed to Iraq. Arch Gen Psychiatry 2011;68:79-89.

9. Brenner LA, Ivins BJ, Schwab K, et al. Traumatic brain injury, posttraumatic stress disorder, and postconcussive symptom reporting among troops returning from Iraq. J Head Trauma Rehabil 2010;25:307-12.

10. Verfaellie M, Lafleche G, Spiro A III, et al. Chronic postconcussion symptoms and functional outcomes in OEF/OIF veterans with self-report of blast exposure. J Int Neuropsychol Soc 2013;19:1-10.

11. Wilk JE, Herrell RK, Wynn GH, et al. Mild traumatic brain injury (concussion), posttraumatic stress disorder, and depression in U.S. soldiers involved in combat deployments: association with postdeployment symptoms. Psychosom Med 2012;74:249-57.

12. Rona RJ, Jones M, Fear NT, et al. Mild traumatic brain injury in UK military personnel returning from Afghanistan and Iraq: cohort and cross-sectional analyses. J Head Trauma Rehabil 2012;27:33-44.

13. Okie S. Traumatic brain injury in the war zone. $N$ Engl J Med 2005;352:2043-7.

14. Jaffee MS, Meyer KS. A brief overview of traumatic brain injury (TBI) and post-traumatic stress disorder (PTSD) within the Department of Defense. Clin Neuropsychol 2009;23:1291-8.

15. Garber BG. Canadian Forces Health Services Advisory Panel on Management of Mild Traumatic Brain Injury in Military Operational Settings: Report. Canadian Forces Web Site 2008. http://cmp-cpm. forces.mil.ca/health-sante/ps/dh-sd/tbi-tcl-eng.asp (accessed 5 Jul 2015).

16. Zamorski MA. Report on the findings of the enhanced post-deployment screening of those returning from Op ARCHER/ Task Force Afghanistan as of 11 February 2011. Ottawa: Department of National Defence, 2011.

17. Schwab KA, Ivins B, Cramer G, et al. Screening for traumatic brain injury in troops returning from deployment in Afghanistan and Iraq: initial investigation of the usefulness of a short screening tool for traumatic brain injury. J Head Trauma Rehabil 2007;22:377-89.

18. Terrio HP, Nelson LA, Betthauser LM, et al. Postdeployment traumatic brain injury screening questions: sensitivity, specificity, and predictive values in returning soldiers. Rehabil Psychol 2011:56:26-31.

19. Schneiderman Al, Braver ER, Kang HK. Understanding sequelae of injury mechanisms and mild traumatic brain injury incurred during the conflicts in Iraq and Afghanistan: persistent postconcussive symptoms and posttraumatic stress disorder. Am J Epidemiol 2008;167:1446-52

20. Spitzer RL, Kroenke K, Williams JB. Validation and utility of a self-report version of PRIME-MD: the PHQ primary care study. Primary Care Evaluation of Mental Disorders. Patient Health Questionnaire. JAMA 1999;282:1737-44. 
21. Kroenke K, Spitzer RL, Williams JB. The Patient Health Questionnaire-2: validity of a two-item depression screener. Med Care 2003;41:1284-92.

22. Lang AJ, Stein MB. An abbreviated PTSD checklist for use as a screening instrument in primary care. Behav Res Ther 2005;43:585-94.

23. Blanchard EB, Jones-Alexander J, Buckley TC, et al. Psychometric properties of the PTSD Checklist (PCL). Behav Res Ther 1996;34:669-73.

24. Zamorski MA, Rusu C, Garber BG. Prevalence and correlates of mental health problems in Canadian Forces personnel who deployed in support of the mission in Afghanistan: findings from postdeployment screenings, 2009-2012. Can J Psychiatry 2014;59:319-26.

25. Castro CA, McGurk D. The intensity of combat and behavioral health status. Traumatology 2007;13:6-23.

26. National Defence and The Canadian Armed Forces: DAOD 5023-0, Universality of Service. http://www.forces.gc.ca/en/about-policiesstandards-defence-admin-orders-directives-5000/5023-0.page (accessed 22 Feb 2106)

27. Canadian Armed Forces Medical Standards (CFP 154). http://www. forces.gc.ca/en/about-policies-standards-medical-occupations/index. page (accessed 22 Feb 2016).

28. Boulos D, Zamorski MA. Military occupational outcomes in Canadian armed forces personnel with and without deployment-related mental disorders. Can J Psychiatry 2016. In press.

29. White IR, Royston P, Wood AM. Multiple imputation using chained equations: issues and guidance for practice. Stat Med 2011;30:377-99.

30. Hosmer DW, Lemeshow S, May S. Applied survival analysis: regression modelling of time-to-event data, 2nd ed. Hoboken: Wiley, 2008.

31. Hertzmark E, Pazaris M, Spiegelman D. The SAS MEDIATE Macro. 3-2-2015. http://www.worksafebc.com/health_care_providers/Assets/ PDF/MTBI.pdf

32. Schoenfeld AJ, Goodman GP, Burks R, et al. The influence of musculoskeletal conditions, behavioral health diagnoses, and demographic factors on injury-related outcome in a high-demand population. J Bone Joint Surg Am 2014;96:e106.

33. Pietrzak RH, Johnson DC, Goldstein MB, et al. Posttraumatic stress disorder mediates the relationship between mild traumatic brain injury and health and psychosocial functioning in veterans of Operations Enduring Freedom and Iraqi Freedom. J Nerv Ment Dis 2009;197:748-53

34. WCB Evidence-Based Practice Group. Mild Traumatic Brain Injury: review of the literature and a look at the WCB of BC data. Released 7 August 2003. http://www.worksafebc.com/health_care_providers/ Assets/PDF/MTBI.pdf (accessed 12 Jun 2015).

35. Cancelliere C, Kristman VL, Cassidy JD, et al. Systematic review of return to work after mild traumatic brain injury: results of the International Collaboration on Mild Traumatic Brain Injury Prognosis. Arch Phys Med Rehabil 2014;95(3 Suppl):S201-9.

36. Bryant RA. Disentangling mild traumatic brain injury and stress reactions. N Engl J Med 2008;358:525-7.

37. McCauley SR, Boake C, Pedroza C, et al. Correlates of persistent postconcussional disorder: DSM-IV criteria versus ICD-10. J Clin Exp Neuropsychol 2008;30:360-79.

38. Belanger HG, Spiegel E, Vanderploeg RD. Neuropsychological performance following a history of multiple self-reported concussions: a meta-analysis. J Int Neuropsychol Soc 2010;16:262-7.

39. Silverberg ND, Lange RT, Millis SR, et al. Post-concussion symptom reporting after multiple mild traumatic brain injuries. $J$ Neurotrauma 2013;30:1398-404.

40. Silverberg ND, Iverson GL. Etiology of the post-concussion syndrome: physiogenesis and Psychogenesis revisited. NeuroRehabilitation 2011:29:317-29.

41. Helmick K. Cognitive rehabilitation for military personnel with mild traumatic brain injury and chronic post-concussional disorder: results of April 2009 consensus conference. NeuroRehabilitation 2010;26:239-55.

42. Ontario Neurotrauma Foundation. Guidelines for mild traumatic brain injury and persistent symptoms. Ontario Neurotruma Foundation. http://www.onf.org/documents/Guidelines20for20Mild20Traumatic 20Brain20Injury20and20Persistent20Symptoms.pdf (accessed 11 Jun 2011).

43. Institute of Medicine. Cognitive Rehabilitation Therapy for Traumatic Brain Injury: evaluating the Evidence. Released 11 October 2011. http://iom.nationalacademies.org/Reports/2011/CognitiveRehabilitation-Therapy-for-Traumatic-Brain-Injury-Evaluating-theEvidence.aspx (accessed 19 May 2015). 